\title{
Long-Term Weight Maintenance Strategies Are Experienced as a Burden by Persons Who Have Lost Weight Compared to Persons with a lifetime Normal, Stable Weight
}

\author{
Maaike Kruseman Noémi Schmutz Isabelle Carrard \\ Department of Nutrition and Dietetics. HES-SO University of Applied Sciences Western \\ Switzerland, Carouge, Switzerland
}

\section{Keywords}

Obesity $\cdot$ Weight loss maintenance $\cdot$ Dietary intake $\cdot$ Perception

\begin{abstract}
Objective: To assess dietary intake, eating patterns, physical activity and eating behaviors, and to explore strategies and perceptions of the experience of weight maintenance in weight loss maintainers (weight loss maintenance (WLM) $\geq 10 \%$ weight loss maintained for $\geq 1$ year) and in matched controls with a lifetime stable normal weight. Methods: Volunteers (32) were recruited by a snowball procedure in this cross-sectional, mixed-methods study. Diet, physical activity, and eating behaviors were assessed with validated questionnaires. Strategies and experiences were investigated during interviews. Descriptive coding, thematic analysis (qualitative data) as well as descriptive analysis and t-tests (quantitative data) were performed. $\boldsymbol{R e}$ sults: Both groups had similar energy and macronutrient consumption. Those in the WLM group reported higher levels of exercise and scored higher on several dimensions of eating disorders. Four themes - 'food choices,' 'quantities and portion control,' 'physical activity', and 'burden' - emerged from the qualitative data. Both groups used similar weight maintenance strategies, but those in the WLM group experienced a higher burden, expressing effortful control which contrasted with the control group's confidence in their internal cues. Conclusion: Our results show an additional burden related with maintaining weight loss compared to keeping a stable normal weight. They provide evidence to devise interventions that will address the difficulty of regulating intake.

(c) 2017 The Author(s)
\end{abstract}

Published by S. Karger GmbH, Freiburg

Prof. Dr. Maaike Kruseman

Department of Nutrition and Dietetics

HES-SO University of Applied Sciences Western Switzerland

Rue des Caroubiers 25, 1227 Carouge, Switzerland

maaike.kruseman@hesge.ch 


\section{Introduction}

Treating obesity is a challenge, mostly because of the difficulty in maintaining weight loss beyond 1 year $[1,2]$. Whereas numerous weight loss interventions have been evaluated and compared, resulting in evidence-based guidelines [3, 4], the process of successful weight loss maintenance (WLM) is still elusive [5, 6]. Despite a growing body of research on this topic, the effective components of WLM interventions are difficult to identify [7, 8]. One reason is that the population of interest is hard to reach, in part because of its small size $[9,10]$, but also because many people lose weight successfully outside structured programs [11] and therefore are difficult to identify and approach.

However, several studies have included 'weight loss maintainers', usually defined as persons who have intentionally lost at least $10 \%$ of their initial body weight and kept it off for at least one year [12]. One major ongoing study is the US-based National Weight Control Registry (NWCR), which started in 1994 and has regularly published on self-reported weight maintenance strategies [13-15], characteristics associated with WLM [16, 17] and the risk factors of weight regain $[18,19]$. In this cohort, the most frequently self-reported strategies of WLM include consuming low-energy and low-fat diets, eating breakfast regularly, following consistent eating patterns, monitoring weight and food intake, and engaging in at least $1 \mathrm{~h}$ of daily physical activity $[12,13,19]$. Likewise, European-based WLM registries have reported decreased energy intake [20], low carbohydrate consumption and regular physical activity [21] as successful strategies. Overall, these studies suggest that a low-energy diet and high levels of physical activity are necessary for WLM. However, these factors were rarely measured precisely or, when they were, gave inconsistent results. For example, Phelan et al. [22] showed low average energy intake in the NWCR $(1,379 \pm 573 \mathrm{kcal}$, approximately $19 \mathrm{kcal} / \mathrm{kg})$, but energy intake in the Portuguese Weight Control Registry were in the normal range $(2,199 \pm$ $840 \mathrm{kcal}$, approximately $30 \mathrm{kcal} / \mathrm{kg}$ ) [21]. Levels of physical activity did not explain this discrepancy (>60 $\mathrm{min} /$ day vs. approximatively $40 \mathrm{~min} /$ day). Other studies that included assessment of physical activity indicate great variability of results $[21,23]$, suggesting that the amount of physical activity necessary to maintain weight loss is highly individual [21]. Another issue is the absence of comparisons with a reference group presenting a stable normal weight. Comparisons have been made with the general populations in some studies $[13,24,25]$, but these included overweight persons not seeking weight loss. While weight loss maintainers have reported dietary restraint and physical activity as their main strategies, it is not well known whether they eat less and move more than individuals with stable normal weight.

Nevertheless, sustaining WLM strategies might have high costs, notably on eating behaviors: the German and the Portuguese Weight Control Registries both showed an overpreoccupation with shape and weight in persons having maintained weight loss compared to the general population (which included overweight persons who did not seek weight loss). They also identified more binge eating and compensatory behaviors than in the general population [24, 25]. In an analysis of 10-year prospective data from the NWCR, Thomas et al. [19] found that higher dietary restraint (i.e., the degree of conscious control applied to regulate eating behavior) and lower disinhibition (i.e., the tendency toward loss of control in eating) seemed necessary to maintain weight loss. Taken together, these data suggest that high levels of control and vigilance, constant monitoring, and discipline are necessary for WLM. On the other hand, qualitative studies assessing perceptions and representations on WLM provide contrasting findings, showing that persons who were able to maintain their weight loss put emphasis on 'lifestyle change rather than being on a diet' [26], moved away from the 'dieting mentality', and reported a 'more relaxed, "no worries approach"'. They 'avoided banning foods from their diet' [27] and mentioned experiencing a 'shift towards a new self' and 'rede- 
Kruseman et al.: Long-Term Weight Maintenance Strategies Are Experienced as a Burden by Persons Who Have Lost Weight Compared to Persons with a lifetime Normal, Stable Weight

fining themselves' [28]. It is striking that results from studies with different approaches seem inconsistent: Quantitative studies imply a possible burden of WLM related to controlled dietary intake and monitoring of body weight, whereas qualitative studies describe a more flexible approach and relaxed attitude. This apparent contradiction could be related to the fact that these factors have been studied distinctly in various samples of weight loss maintainers recruited in different, single settings.

Therefore, a more comprehensive examination would be useful to better understand what WLM entails, and to target specific needs when designing WLM interventions. Our goal was to assess dietary intake, daily eating patterns, physical activity and eating behaviors, and to explore strategies and perceptions of the experience of weight maintenance in two groups: one group of individuals with WLM, and one group of individuals with a lifetime, stable normal weight considered as a control group.

\section{Material and Methods}

We used a mixed-method design with quantitative tools to assess dietary intake, physical activity, and eating behaviors as well as a qualitative methodology to explore daily eating patterns, strategies, and experiences of weight maintenance. This was an exploratory study in which the data were intended to support a grant proposal for a larger investigation. The study protocol was approved by the Cantonal Ethics Committee on Research.

\section{Recruitment Strategy}

With the goal of describing weight maintenance across a variety of situations, we used a snowball procedure to sample at least 15 participants per group, as opposed to recruiting in one or two settings, which could lead to selection bias. Power was not calculated a priori because this was an exploratory study; so we wanted to include as many participants as possible with the funding available. We recruited the first participants by word of mouth through the investigators' networks. Each participant was asked to think of someone they knew who could also be eligible, either in the WLM or the control group.

The inclusion criteria to participate in the WLM group were initial BMI $\geq 25 \mathrm{~kg} / \mathrm{m}^{2}$ and intentional weight loss of at least $10 \%$ of initial weight, maintained for at least 12 months, excluding bariatric surgery. The controls' inclusion criteria were BMI between 18.5 and $24.9 \mathrm{~kg} / \mathrm{m}^{2}$ and adult lifetime stable weight of \pm 5 $\mathrm{kg}$, apart from pregnancies. The participants in both groups had to live or work in the French-speaking part of Switzerland and were matched by sex, age, and socioeconomic status.

\section{Procedures}

The participants were included after a screening interview performed by phone. They self-reported weight and height, and those in the WLM group provided pictures (similarly as in the NWCR) by email or social media to ascertain self-reported weight change. When no pictures were available, testimonies of caregivers (e.g., physicians, dieticians) were accepted. The study goals and procedures were explained, and a 2-hour appointment was arranged, which took place at either our office or the participant's home. The meeting started with the formal information about the study and the informed consent being signed, after which an audio-recorded semi-structured interview was performed. At the end of the interview, a set of 17 questionnaires was given to the participant to be filled out at home, together with a pre-stamped envelope. Data from four questionnaires were used in this study. If the questionnaires were not returned after 7 days, a reminder was sent by email. If the questionnaires were still not returned, up to two phone calls were made. All of the questionnaires were entered manually into pre-coded databases (double entry). Individual feedback was mailed to each participant, together with a department store voucher worth CHF 20.00 (approximately equivalent to EUR 18.00) as compensation for their participation.

\section{Measures}

A short questionnaire was used to collect sociodemographic data on sex, age, country of origin, family status, education [29], profession, and income [30]. These data were used to describe our study population and to match the participants in both groups. 
Kruseman et al.: Long-Term Weight Maintenance Strategies Are Experienced as a Burden by Persons Who Have Lost Weight Compared to Persons with a lifetime Normal, Stable Weight

Dietary Intake

The Food Frequency Questionnaire (FFQ) [31] is a 97-item questionnaire used to self-report dietary intake; it has been developed and validated in the Geneva population and widely used in the French-speaking part of Switzerland for research and surveys [32]. The food items contributing substantially to the nutritional intake of a representative sample of the population of the State of Geneva (providing at least $90 \%$ of the calories, proteins, carbohydrates, total fat, dietary cholesterol, alcohol, vitamin D, and retinol consumed by the population) are part of the FFQ. The questionnaire assesses the respondent's diet during the previous month by asking the respondent to choose the frequency of consumption for each food item (never during the last 4 weeks, once a month, 2-3 times per month, 1-2 times per week, 3-4 times per week, once a day, twice or more per day) and to estimate the portion they consumed (smaller, equal, or larger than the displayed reference portion). Eight food groups were defined (protein sources, starches, fats, low fat, vegetables, fruits, sugar and sweets, artificially sweetened), and daily portions were summed up to calculate the respondent's average consumption of each food group. Average daily intakes of calories, proteins, carbohydrates, total fat, and alcohol were calculated with the food composition table developed for the FFQ [31].

\section{Daily Eating Patterns}

Usual frequencies of daily eating occasions and nibbling during the last month were assessed during the interviews. Meals and snacks were defined as any structured food intake (including lunches, dinners, and snacks). Breakfast was defined as any caloric intake within $1 \mathrm{~h}$ following awakening. Nibbling was defined as irregular, unplanned intake without a clear start or ending.

\section{Physical Activity}

The Global Physical Activity Questionnaire (GPAC) [33] is a 16-item questionnaire that is used in more than 100 countries and was developed by the World Health Organization to assess the intensity, frequency and duration of physical activity related to the professional, transport and leisure domains during a typical week. These parameters are combined in a standardized SPSS routine to classify subjects according to three levels of physical activity:

- Vigorous: intense physical activity reaching at least 1,500 MET-min/week, at least 3 days a week OR moderate to intense physical activity reaching at least 3,000 MET-min/week.

- $\quad$ Moderate: at least 20 mins of intense physical activity at least 3 days a week OR at least 30 mins of moderate physical activity or walking, at least 5 days a week OR at least 5 days/week of walking or moderate to intense physical activity, reaching at least 600 MET-min/week.

- Sedentary: none of the above criteria are reached [33].

\section{Eating Behaviors}

The Three-Factor Eating Questionnaire (TFEQ) [34] is a 51-item questionnaire initially developed to evaluate eating behaviors among persons suffering from obesity. Three scores can be calculated, corresponding to the subscales of 'restraint' (21 items), 'disinhibition' (16 items) and 'hunger' (14 items). Higher scores indicate higher levels of 'restraint', 'disinhibition' and 'hunger', but no cut-off points are defined. The French version of the questionnaire has been validated [35]. For the purpose of our study and similarly to the NWCR [19], we used the 'restraint' and 'disinhibition' subscales.

\section{Strategies and Experiences}

One of the investigators (one psychologist and two dieticians) conducted individual semi-structured interviews with each participant during one-on-one sessions lasting between 1 and $2 \mathrm{~h}$. An interview guide with open-ended questions (previously tested among 5 persons who met the WLM criteria and were not part of this study), was used to cover weight changes over time, successful weight loss (WLM group only), weight maintenance (strategies, rules, or habits that helped them to manage their weight, difficulties they experienced in maintaining their weight), and how they anticipated the future. The interview guide included questions such as: 'Tell me about how you eat to maintain your body weight.'; 'What helps you to maintain your weight? What makes it difficult or hinders you?'; 'Could you describe what you consider as rules in your diet?'.

\section{Data Analyses}

Quantitative data were analyzed with SPSS (version 22.0, 2013, IBM Corp. Armonk, NY, USA). The descriptive results were expressed as frequencies ( $\mathrm{n} ; \%$ ) or means \pm SD after checking for normality of distribution. Comparisons of continuous variables were made for descriptive purposes. As data distribution was 
normal, the comparisons between groups were tested with t-tests. No categorical comparisons were carried out because of the insufficient number of subjects per cell. Energy intake is expressed as total kilocalories and as kilocalories per kilogram of body weight. Macronutrient and alcohol intakes are expressed as grams per day and as a percentage of total energy intake.

The interviews were transcribed verbatim. Two investigators performed the descriptive coding [36] of the interview transcripts using MaxQDA software (version 11, 1989-2014; VERBI Software-Consult-Sozialforschung $\mathrm{GmbH}$, Berlin, Germany). First, the strategies reported by the participants were listed and summarized into main codes to count how many participants used each of them. Second, the interviews were coded to reflect the participants' experiences with minimal interpretations. Both principal investigators coded the first two interviews together to reach a good level of concordance. Memos were created for each code definition. Then, each investigator coded half of the dataset and checked the codes of the other half. When needed, the codes or code definitions were clarified or modified by consensus. Finally, all of the codes were reviewed and grouped into main themes. Emblematic citations were extracted and reproduced in the results section, with the participant's gender and age in brackets.

\section{Results}

\section{Sample Characteristics}

Between June and December 2013, we included 36 volunteers (18 in each group) through 14 different contacts. Two participants in the WLM group did not return the questionnaires, and the data of 2 controls were excluded because their dietary intakes seemed unrealistic ( 7 $\mathrm{kcal} / \mathrm{kg}$ and $110 \mathrm{kcal} / \mathrm{kg}$ body weight per day). The remaining 32 participants ( 20 women, 12 men) were Caucasian and mostly Swiss ( $\mathrm{n}=25 ; 78 \%$ ) or from a nearby European country $(\mathrm{n}=7 ; 22 \%)$. Most lived in Geneva or its suburbs $(\mathrm{n}=20 ; 62 \%)$. The others lived either in small cities ( $n=5 ; 16 \%)$ or in the countryside ( $n=7 ; 22 \%)$, up to $150 \mathrm{~km}$ away from Geneva.

The respondents in the WLM group had higher BMI than the controls $(25.5 \pm 2.9$ vs. 21.0 $\pm 1.9 ; \mathrm{p}<0.001$ ) but all had lost at least $10 \%$ of their weight (range $12-35 \%$ ). Table 1 displays detailed characteristics of the participants.

\section{Dietary Intake, Daily Eating Patterns, Physical Activity, and Eating Behaviors}

Among the eight food groups defined in the FFQ, foods that belonged to the 'protein sources' and 'low fat' groups were consumed significantly more often among the participants in the WLM group than among those in the control group, whereas 'sugar and sweets' were almost equally consumed among both groups. Artificially sweetened products were exclusively consumed by participants from the WLM group. The groups' energy and nutrient intakes were similar when adjusted for body weight (table 2).

The WLM group did not exhibit any specific daily eating pattern in terms of meal frequencies or nibbling in comparison with the controls (table 2).

The GPAC questionnaire showed that participants of both groups engaged, on average, in more than 1 h of daily physical activity (WLM group $96 \pm 67$; control group $66 \pm 42 \mathrm{~min}$ ). Eight participants in the WLM group (53\%) and $3(19 \%)$ in the control group reported a vigorous level of physical activity, whereas $1(6 \%)$ and $6(38 \%)$ were considered sedentary, respectively (table 2).

The participants in the WLM group had higher scores in the 'restraint' and 'disinhibition' subscales of the TFEQ than the controls, reflecting conscious effort to restrict food intake and more overeating and loss of control (table 2).

Strategies and Experiences

Four major themes emerged from the qualitative data: 'food choices', 'quantities and portion control', 'physical activity' and 'burden'. The latter was only found in the WLM group. 


\begin{tabular}{|c|c|c|c|}
\hline \multicolumn{4}{|l|}{ Obes Facts 2017;10:373-385 } \\
\hline DOI: $10.1159 / 000478096$ & \multicolumn{3}{|c|}{$\begin{array}{l}\text { (c) } 2017 \text { The Author(s). Published by S. Karger GmbH, Freiburg } \\
\text { www.karger.com/ofa }\end{array}$} \\
\hline \multicolumn{4}{|c|}{$\begin{array}{l}\text { Kruseman et al.: Long-Term Weight Maintenance Strategies Are Experienced as a } \\
\text { Burden by Persons Who Have Lost Weight Compared to Persons with a lifetime } \\
\text { Normal, Stable Weight }\end{array}$} \\
\hline & & WLM & Controls \\
\hline Male/female ratio (n) & & $6 / 10$ & $6 / 10$ \\
\hline Age, years & & $38.1 \pm 7.9$ & $39.4 \pm 10.0$ \\
\hline \multicolumn{4}{|l|}{ Weight history } \\
\hline Current weight, kg* & & $74.5 \pm 11.8$ & $62.5 \pm 10.0$ \\
\hline BMI, $\mathrm{kg} / \mathrm{m}^{2 *}$ & & $25.5 \pm 2.9$ & $21.0 \pm 1.9$ \\
\hline Weight loss, kg & & $25.2 \pm 11.7$ & - \\
\hline Years of weight mainte & lance, years & $3.5 \pm 3.1$ & - \\
\hline \multicolumn{4}{|c|}{ Family status (n;\%) } \\
\hline \multirow{2}{*}{\multicolumn{2}{|c|}{$\begin{array}{l}\text { Living alone (vs. married or partnership) } \\
\text { Children yes }\end{array}$}} & $8(50 \%)$ & $4(25 \%)$ \\
\hline & & $10(62.5 \%)$ & $10(62.5 \%)$ \\
\hline \multicolumn{4}{|l|}{ Education level } \\
\hline \multicolumn{2}{|c|}{ Upper Secondary } & $10(62.5 \%)$ & $6(37.5 \%)$ \\
\hline \multicolumn{2}{|c|}{ Tertiary (university or equivalent) } & $6(37.5 \%)$ & $10(62.5 \%)$ \\
\hline \multicolumn{4}{|l|}{ Employement category } \\
\hline \multicolumn{2}{|l|}{ Executive } & $4(25 \%)$ & $4(25 \%)$ \\
\hline \multicolumn{2}{|l|}{ Employee } & $10(62.5 \%)$ & $10(62.5 \%)$ \\
\hline \multicolumn{2}{|l|}{ Self-employed } & $1(6 \%)$ & $1(6 \%)$ \\
\hline \multicolumn{4}{|c|}{ Income categories (monthly) } \\
\hline \multicolumn{2}{|c|}{$<5,000 \mathrm{CHF}$} & $3(19 \%)$ & $2(12.5 \%)$ \\
\hline \multicolumn{2}{|l|}{$5,000-9,499 \mathrm{CHF}$} & $6(37.5 \%)$ & $8(50 \%)$ \\
\hline \multicolumn{2}{|l|}{$\geq 9,500 \mathrm{CHF}$} & $3(19 \%)$ & $5(31 \%)$ \\
\hline \multicolumn{2}{|l|}{ Refused to answer } & $4(25 \%)$ & $1(6 \%)$ \\
\hline
\end{tabular}

Table 1. Participant characteristics with WLM compared to stable normalweight controls $(\mathrm{N}=16$ in each group: 6 men and 10 women)

\section{Food Choices}

Participants in both groups referred to conscious food choices intended to maintain their weight, like trying to eat plenty of fruits and vegetables (10 in the WLM group (63\%); 11 in the control group (69\%)) and cutting down on fats (14 in the WLM group (88\%); 11 in the control group (69\%)) and snacks (13 in the WLM group (81\% ; 7 in the control group (44\%)). Participants in the WLM group mentioned choosing protein-rich food items more often $(10$ in the WLM group (63\%); 1 in the control group (6\%)), avoiding carbohydrates (13 in the WLM group (81\%); 3 in the control group (19\%)) and using artificially sweetened products (6 in the WLM group (38\%); 0 in the control group). Sub-themes emerged from the discourse of the respondents according to their group: 'rules' in the WLM group and 'habits' in the control group.

Rules versus Habits

When talking about their food choices, women and men in the WLM group referred to effortful cognitive control with precise rules about which foods they could eat and which they had to avoid: '(...) Every Thursday you eat, until the end of your life, proteins. Every Thursday is protein day' (woman, 42). They often used definite terms like 'banning,' 'never eating' and 'forbidden'. Emblematic quotes include: 'Chocolate bars? I abolished those!' (man, 46), '(...) I cut out all soft drinks, ice-tea, I banned all that from my diet' (man, 37), 'For now, I don't eat carbohydrates. My idea is not to eat any at all, ever' (woman, 48). On the contrary, the controls referred to their food choices as healthy habits or personal preferences. The purposeful 
Kruseman et al.: Long-Term Weight Maintenance Strategies Are Experienced as a Burden by Persons Who Have Lost Weight Compared to Persons with a lifetime Normal, Stable Weight

Table 2. Dietary intake, eating patterns, physical activity and eating behaviors (mean \pm SD) of 16 participants with WLM and 16 stable normal-weight controls

\begin{tabular}{|c|c|c|c|}
\hline & WLM & Control & $\begin{array}{l}\mathrm{p} \text { value } \\
\text { (t-test) }\end{array}$ \\
\hline \multicolumn{4}{|l|}{ Food group intake, $g$} \\
\hline Protein sources & $396 \pm 287$ & $223 \pm 107$ & 0.037 \\
\hline Starches & $205 \pm 92$ & $239 \pm 98$ & 0.348 \\
\hline Fats & $114 \pm 57$ & $125 \pm 60$ & 0.592 \\
\hline Sugar and sweets & $243 \pm 321$ & $224 \pm 178$ & 0.845 \\
\hline Low fat & $89 \pm 79$ & $38 \pm 34$ & 0.029 \\
\hline Artificially sweetened & $234 \pm 45$ & 0 & 0.093 \\
\hline Vegetables & $135 \pm 69$ & $131 \pm 72$ & 0.904 \\
\hline Fruits & $340 \pm 408$ & $252 \pm 152$ & 0.451 \\
\hline \multicolumn{4}{|l|}{ Energy intake } \\
\hline Total energy intake & $1,704 \pm 671$ & $1,592 \pm 423$ & 0.577 \\
\hline Weight adjusted energy intake, $\mathrm{kcal} / \mathrm{kg}$ & $23.1 \pm 8.7$ & $25.4 \pm 5.0$ & 0.356 \\
\hline Protein intake, $\mathrm{g} / \mathrm{kg}$ & $1.14 \pm 0.54$ & $0.96 \pm 0.27$ & 0.263 \\
\hline Protein intake, \% TEI & $20 \pm 4.1$ & $16 \pm 2.4$ & 0.002 \\
\hline Carbohydrates intake, $\mathrm{g}$ & $185.2 \pm 89.9$ & $174.4 \pm 48.5$ & 0.674 \\
\hline Carbohydrates intake, \% TEI & $44 \pm 10.4$ & $47 \pm 5.8$ & 0.397 \\
\hline Lipid intake, $g$ & $65.9 \pm 27.7$ & $63.4 \pm 22.1$ & 0.780 \\
\hline Lipid intake, \% TEI & $36 \pm 6.9$ & $38 \pm 5.6$ & 0.516 \\
\hline Alcohol intake, g & $5.35 \pm 5.6$ & $11.98 \pm 14.4$ & 0.102 \\
\hline \multicolumn{4}{|l|}{ Eating patterns, $n(\%)$} \\
\hline No breakfast & $4(25 \%)$ & $5(31 \%)$ & \\
\hline 2-3 structured meals/snacks & $7(44 \%)$ & $9(56 \%)$ & \\
\hline 4-6 structured meals/snacks & $8(50 \%)$ & $7(44 \%)$ & \\
\hline Daily nibbling & $6(38 \%)$ & $4(25 \%)$ & \\
\hline No defined eating pattern & $1(6 \%)$ & 0 & \\
\hline \multicolumn{4}{|l|}{ Physical activity level, $n(\%)$} \\
\hline Sedentary & $1(6 \%)$ & $6(38 \%)$ & \\
\hline Moderate & $6(40 \%)$ & $7(44 \%)$ & \\
\hline Vigorous & $8(53 \%)$ & $3(19 \%)$ & \\
\hline \multicolumn{4}{|l|}{ TFEQ Subscales scores } \\
\hline Restraint & $10.5 \pm 5.1$ & $5.1 \pm 3.6$ & 0.002 \\
\hline Disinhibition & $7.6 \pm 3.2$ & $4.4 \pm 2.7$ & 0.005 \\
\hline
\end{tabular}

avoidance of food groups was uncommon and seemed to be merely a default choice among the controls, who considered it to be 'natural' and 'not really an effort'. They also refuted the term 'rules' and referred to pleasure and taste when describing their food choices: 'When I was a kid I didn't like vegetables too much, but now I really like them, so it's easy' (man, 28). 'I don't drink soft drinks, but it's not a big effort as I don't like them so much' (woman, 43). 'It's like fried food, I am not attracted to fried food (...) so it's pretty easy, I just don't want to eat that stuff. (...)' (woman, 43).

\section{Quantities and Portion Control}

Among the participants, 21 spontaneously mentioned the quantities of food they consumed and their portion size control, including 9 from the WLM group (56\%) and 12 from the control group (75\%). Again, sub-themes emerged that were more specifically related to each group: 'vigilance' (WLM group) and 'confidence' (control group). 
Kruseman et al.: Long-Term Weight Maintenance Strategies Are Experienced as a Burden by Persons Who Have Lost Weight Compared to Persons with a lifetime Normal, Stable Weight

Vigilance versus Confidence

Those in the WLM group expressed constant vigilance and intention to adjust their intake. They described difficulties with controlling quantities of particularly palatable food, despite applying strategies like buying single-portion packages and using smaller plates. 'Each thing that enters my mouth, I'm thinking, how many calories is this gonna be, what on earth can I eat tonight to compensate, or tomorrow?' (woman, 44). 'Over the week, I eat a certain amount of [Weight Watcher] points, I'm like a walking calculator' (woman, 30). They also referred to the quantities they used to eat before their weight loss: 'Compared to 6 years ago, it's a drastic reduction' (man, 27). They strove to acquire the ability to regulate quantities more easily: 'I'd like to learn how to enjoy eating those nice things, how to manage the quantity and frequencies' (woman, 29). Those in the control group considered internal cues to be sufficient for regulating their intake and determining when their consumption was excessive, and they expressed confidence that the quantities they consumed would balance out naturally over their next few meals: 'I don't need to control things, I mean... not mentally. There is, for me, a physical regulation. (...). I sort of trust it' (woman, 29). The respondents in the control group also referred to cognitive control but did not experience it as an effort: 'No excess. A constant attention, but without giving yourself a headache' (man, 51).

\section{Physical Activity}

Almost all of the participants (15 in the WL group (94\%); 13 in the control group (81\%)) mentioned sports or physical activity as a strategy for weight maintenance. Sub-themes were: 'scheduled changes' (WLM group) and 'pleasurable habits' (control group).

\section{Scheduled Changes versus Pleasurable Habits}

In the WLM group, current physical activity was different from what participants were used to before weight loss, and they had established some structure (days and/or duration): 'I practice much more sports than before, at least twice a week, 2 h each time' (woman, 42). 'Every Tuesday, I play badminton; and on Fridays, I started running' (man, 46). On the other hand, most of the controls had always practiced physical activity and sports: 'Ohyes, I practice sports. I always did, but I do not have one activity in particular, I enjoy the variety' (woman, 45). Among the controls, physical activity was also more often inserted into their daily lives: ' $I I$ have] no parking close to work. So I ride my bicycle. I have no other option, even when I'm tired or if it snows or rains. It's just like that' (woman, 45). In the WLM group, the participants did not mention particularly liking or disliking physical activity, whereas the controls often qualified their activities as a pleasure : 'It's true. I love sports, I think I couldn't live without them' (man, 28). 'I like running. I like swimming. I often go to the gym. I'd say when I have free time I give priority to physical activity' (woman, 52).

Burden

'Burden', already discernible within the previous themes in terms of attention, emerged as a theme in and of itself among the WLM group. To them, 'burden' referred to the following issues: the hardship of maintaining their weight - 'I'm full of good intentions, but in practice, it is always difficult to stick to them. I often have difficulty holding on' (woman, 29); the anxiety of gaining weight again - 'I feel anxious about regaining my weight, about returning to my old ways, about letting myself go completely and reaching more than $100 \mathrm{~kg}$ again. If I weighed over $100 \mathrm{~kg}$ again, I think I'd go crazy' (man, 37); and the loneliness and unfairness of their situation - 'I'd like to be one of those persons who can eat everything and never gain one gram' (woman, 44), 'The comments, they can have an annoying side, because you get the feeling of not being understood; the feeling that people do not realize what it represents [to maintain weight loss]' (woman, 30) and 'You have the feeling you have to control everything, unlike someone who 
Kruseman et al.: Long-Term Weight Maintenance Strategies Are Experienced as a Burden by Persons Who Have Lost Weight Compared to Persons with a lifetime Normal, Stable Weight

has no weight problems, who doesn't have to go to too much trouble' (man, 31). The importance of self-control for self-esteem also appeared: 'What is also difficult is to have done all that and not have the image you were expecting, because in my head, after having lost all that weight, I should have been perfect, but no' (woman, 30). Such concerns were not found in the control group.

\section{Discussion}

In this study, we used a mixed-method approach to assess dietary intake, daily eating patterns, physical activity and eating behaviors, and to explore strategies and perceptions related to the experience of weight maintenance among persons who have lost weight and individuals with a lifetime stable normal weight. Our main finding is that, despite purposeful food choices, those in the WLM group had similar nutritional intake than normal weight controls. Our second finding is that the reported weight maintenance strategies are not specific to WLM, but are also used to maintain a lifetime normal weight. However, the implementation of these strategies by individuals in the WLM group necessitated burdensome stratagems and higher vigilance.

The quantitative data on dietary intake reflected the WLM group's preferences for protein sources and low-fat preparations. They also consumed artificially sweetened foods, whereas controls did not. This reflects a conscious effort to choose 'weight loss diet foods', which might have been acquired during the weight loss process $[37,38]$. These different food choices did not result in measurably lower energy intake or different nutrient intake when compared to the normal-weight controls, and this might indicate that the individuals in the WLM group needed these strategies to avoid excessive consumption of fats and sugar. It is also possible that, while avoiding the food items they perceived as unhealthy or fattening, they ate more of the other foods, increasing the total nutrient and energy intake. In this case, care-givers should make sure that persons trying to maintain weight loss have accurate knowledge about dietary needs, nutritional value of foods, and adequate portion sizes, as this could help them choosing from a larger variety of foods and preparations. A more detailed analysis of their food intake, by food diary for example, would give more information on this matter.

Daily eating patterns varied widely within the groups and did not reveal any specificity associated with WLM. This was also true for the consumption or avoidance of breakfast, unlike what has been shown in the NWCR [15] and tends to show that individuals have to find their own eating rhythm that allows them to maintain their weight, as has been suggested by others [25, 39].

The participants in both groups considered physical activity to be necessary for weight maintenance and dedicated a considerable amount of time to it. Those in the WLM group were more likely to engage in higher-intensity physical activity and for a longer duration than the controls. This result might indicate a vulnerability to weight gain in the WLM group. This is also suggested by the NWCR data, in which those with the highest physical activity reported more dietary strategies to maintain their weight loss [23]. It is possible that after weight loss, some individuals struggle with lower resting energy expenditure, which has been documented during or shortly after weight loss $[40,41]$. A recent publication suggests that this phenomenon persists even after several years of weight loss [42], but these data should be confirmed and compared with the resting energy expenditure of a control group with stable normal weight. In this pilot study, we were not able to measure resting energy expenditure. This, together with the assessment of body composition, should be done in the future among WLM and normal-weight controls, in order to assess whether the struggle to maintain weight loss is related to a lower metabolism. 
Kruseman et al.: Long-Term Weight Maintenance Strategies Are Experienced as a Burden by Persons Who Have Lost Weight Compared to Persons with a lifetime Normal, Stable Weight

The WLM group scored higher on the scales evaluating eating behaviors, similarly as in two European registries $[24,25]$. The higher scores obtained on the 'restraint' scales reflects the intention to restrict or favor the intake of particular food groups, and are consistent with the results of dietary intake. 'Restraint' can manifest itself as a rigid control in relation to an eating behavior, which is characterized by a dichotomous, all-or-nothing approach to eating and dieting, and entails that some foods are excluded from the diet or by a flexible control in relation to an eating behavior, which is described as a more graduated approach to eating and dieting, in which all types of food can be eaten but with a control on the quantity [43]. High rigid control on eating behavior has been related with high 'disinhibition' scores [43] which was also observed in our WLM group. The fact that these behaviors reinforce each other, imprisoning the individual in a vicious circle [43], might explain why similar energy intake was observed in the WLM and the control groups in our study, despite high 'restraint'. Therefore, the ability to exert flexible control might be a desirable goal and could be encouraged in the WLM group. The concept of mindful eating, which promotes eating in a manner that balances individual nutritional needs, hunger, satiety, appetite, and pleasure has shown encouraging preliminary findings [44-46]. It could be a helpful approach, but should be carefully evaluated in the long term, because any alteration in the WLM strategies could also result in undesirable outcomes.

The qualitative data give more insight into what it means to maintain weight loss in the long run. The discourse of the WLM group reflected an effortful control and a constant vigilance, whereas the normal-weight controls expressed a more relaxed attitude. However, the control group also paid attention to their intake and food choices, similarly to what has been shown by others [47-49]. This was also true for physical activity, as those in the WLM group scheduled specific activities, whereas those in the control group were more active on a daily basis. Finally, the fear of regaining weight and the fact that weight loss maintainers did not always feel understood in their struggle should be taken into account when devising WLM interventions. It is possible that developing long-term support, for example in the form of peer-groups, might alleviate the burden experienced by persons maintaining weight loss, as suggested by Hindle et al. [27].

This study has some limitations. Most importantly, the dietary measure is prone to bias because it relies on memory and necessitates the ability to estimate monthly frequencies and portions [50]. The rather low energy intake in our sample indicate an underestimation of the intakes, as is usually the case with food frequency questionnaires [50]. Therefore, the absolute results of dietary intake should be considered with great caution. However, as the FFQ was used in both groups, the comparison of their intakes can be valuable. Moreover, as underreporting has been related to weight loss history and dietary restraint $[51,52]$, the WLM group might have underestimated their intake to a larger extent than the controls. In this case, the real energy intake might be higher in the WLM group than in the controls, which would stress the importance of addressing 'restraint' and 'disinhibition' in this group. Another limitation is the higher BMI of the WLM group, which could have contributed to their sense of burden by increasing the desire to lose more weight.

The sample size is a limitation with regard to the quantitative data, and the power is insufficient to relate subgroups characteristics and strategies. Also, the comparisons should be considered with caution. However, the number of participants was large compared to other qualitative studies about WLM, and limited generalizability is normally the case in qualitative studies [36].

Among the strengths of this study is the complementarity of the quantitative and qualitative methods used. Another forte is the snowball procedure we used for recruiting in the community, which allowed for a heterogeneous sample, including men, and provided rich data. Other strengths include matching the individuals of each group, asking for proof of WLM and using validated questionnaires. 


\section{Conclusion}

This study shows that there is an additional burden to maintaining weight loss compared to keeping a stable normal weight over time. Both necessitate self-control and conscious choices, but, even after $\mathrm{t} 3.5$ years, weight loss maintainers endure a high level of vigilance to stick to their strategies, whereas persons with a lifetime stable normal weight display a more relaxed attitude and the ability to adjust their intake more intuitively. In spite of these unequal efforts, energy and nutrient intakes do not differ between groups. Long-term changes in resting energy expenditure after WLM are unknown and should be explored. Research should also focus on the long-term effect of various interventions on the burden of WLM, such as promoting mindful eating, increasing the ability to choose appropriate portions from a variety of foods instead of rigidly selecting/avoiding certain types of food, and providing long-term support.

\section{Disclosure Statement}

The authors declare having no conflict of interest.

\section{References}

1 Anderson JW, Konz EC, Frederich RC, Wood CL: Long-term weight-loss maintenance: a meta-analysis of US studies. Am J Clin Nutr 2001;74:579-584.

2 Franz MJ, VanWormer JJ, Crain AL, Boucher JL, Histon T, Caplan W, Bowman JD, Pronk NP: Weight-loss outcomes: a systematic review and meta-analysis of weight-loss clinical trials with a minimum 1-year followup. J Am Diet Assoc 2007;107:1755-1767.

3 Yumuk V, Tsigos C, Fried M, Schindler K, Busetto L, Micic D, Toplak H, Obesity Management Task Force of the EASO: European guidelines for obesity management in adults. Obes Facts 2015; 8:402-424.

4 Jensen MD, Ryan DH, Apovian CM, Ard JD, Comuzzie AG, Donato KA, Hu FB, Hubbard VS, Jakicic JM, Kushner RF, Loria CM, Millen BE, Nonas CA, Pi-Sunyer FX, Stevens J, Stevens VJ, Wadden TA, Wolfe BM, Yanovski SZ: 2013 AHA/ACC/TOS guideline for the management of overweight and obesity in adults. J Am Coll Cardiol 2014;63:2985-3023.

5 MacLean PS, Wing RR, Davidson T, Epstein L, Goodpaster B, Hall KD, Levin BE, Perri MG, Rolls BJ, Rosenbaum M, Rothman AJ, Ryan D: NIH working group report: innovative research to improve maintenance of weight loss. Obesity (Silver Spring) 2015;23:7-15.

6 Raynor HA, Champagne CM: Position of the Academy of Nutrition and Dietetics: interventions for the treatment of overweight and obesity in adults. J Acad Nutr Diet 2016;116:129-147.

7 Dombrowski SU, Knittle K, Avenell A, Araujo-Soares V, Sniehotta FF: Long term maintenance of weight loss with non-surgical interventions in obese adults: systematic review and meta-analyses of randomised controlled trials. BMJ 2014;348:g2646.

8 Peirson L, Fitzpatrick-Lewis D, Ciliska D, Usman Ali M, Raina P, Sherifali D: Strategies for weight maintenance in adult populations treated for overweight and obesity: a systematic review and meta-analysis. CMAJ Open 2015;3:E47-54.

9 McGuire MT, Wing RR, Hill JO: The prevalence of weight loss maintenance among American adults. Int J Obes Relat Metab Disord 1999;23:1314-1319.

10 de Zwaan M, Hilbert A, Herpertz S, Zipfel S, Beutel M, Gefeller O, Muehlhans B: Weight loss maintenance in a population-based sample of German adults. Obesity (Silver Spring) 2008;16:2535-2540.

11 Brownell KD, Rodin J: The dieting maelstrom. Is it possible and advisable to lose weight? Am Psychol 1994; 49:781-791.

12 Wing RR, Hill JO: Successful weight loss maintenance. Annu Rev Nutr 2001;21:323-341.

13 Shick SM, Wing RR, Klem ML, McGuire MT, Hill JO, Seagle H: Persons successful at long-term weight loss and maintenance continue to consume a low-energy, low-fat diet. J Am Diet Assoc 1998;98:408-413.

14 Wing RR, Phelan S: Long-term weight loss maintenance. Am J Clin Nutr 2005;82(1 suppl):222S-225S.

15 Wyatt HR, Grunwald GK, Mosca CL, Klem ML, Wing RR, Hill JO: Long-term weight loss and breakfast in subjects in the National Weight Control Registry. Obes Res 2002;10:78-82.

16 Klem ML, Wing RR, McGuire MT, Seagle HM, Hill JO: A descriptive study of individuals successful at long-term maintenance of substantial weight loss. Am J Clin Nutr 1997;66:239-246. 
Kruseman et al.: Long-Term Weight Maintenance Strategies Are Experienced as a Burden by Persons Who Have Lost Weight Compared to Persons with a lifetime Normal, Stable Weight

17 Ogden LG, Stroebele N, Wyatt HR, Catenacci VA, Peters JC, Stuht J, Wing RR, Hill JO: Cluster analysis of the National Weight Control Registry to identify distinct subgroups maintaining successful weight loss. Obesity (Silver Spring) 2012;20:2039-2047.

18 McGuire MT, Wing RR, Klem ML, Lang W, Hill JO: What predicts weight regain in a group of successful weight losers? J Consult Clin Psychol 1999;67:177-185.

19 Thomas JG, Bond DS, Phelan S, Hill JO, Wing RR: Weight-loss maintenance for 10 years in the National Weight Control Registry. Am J Prev Med 2014;46:17-23.

20 Soini S, Mustajoki P, Eriksson JG: Weight loss methods and changes in eating habits among successful weight losers. Ann Med 2016;48:76-82.

21 Santos I, Vieira PN, Silva MN, Sardinha LB, Teixeira PJ: Weight control behaviors of highly successful weight loss maintainers: the Portuguese Weight Control Registry. J Behav Med 2017;40:366-371.

22 Phelan S, Wyatt HR, Hill JO, Wing RR: Are the eating and exercise habits of successful weight losers changing? Obesity (Silver Spring) 2006;14:710-716.

23 Catenacci VA, Odgen L, Phelan S, Thomas JG, Hill J, Wing RR, Wyatt H: Dietary habits and weight maintenance success in high versus low exercisers in the National Weight Control Registry. J Phys Act Health 2014;11: 1540-1548.

24 Vieira PN, Silva MN, Mata J, Coutinho SR, Santos TC, Sardinha LB, Teixeira PJ: Correlates of health-related quality of life, psychological well-being, and eating self-regulation after successful weight loss maintenance. J Behav Med 2013;36:601-610.

25 Feller S, Muller A, Mayr A, Engeli S, Hilbert A, de Zwaan M: What distinguishes weight loss maintainers of the German Weight Control Registry from the general population? Obesity (Silver Spring) 2015;23:1112-1118.

26 McKee H, Ntoumanis N, Smith B: Weight maintenance: self-regulatory factors underpinning success and failure. Psychol Health 2013;28:1207-1223.

27 Hindle L, Carpenter C: An exploration of the experiences and perceptions of people who have maintained weight loss. J Hum Nutr Diet 2011;24:342-350.

28 Ogden J, Hills L: Understanding sustained behavior change: the role of life crises and the process of reinvention. Health 2008;12:419-437.

29 UNESCO Institute for Statistics: International Standard Classification of Education. Montreal, UNESCO, 2012,

30 Office Cantonal de la Statistique: Enquête suisse sur la structure des salaires à Genève. Geneva, OCSTAT, 2015,

31 Morabia A, Bernstein M, Kumanyika S, Sorenson A, Mabiala I, Prodolliet B, Rolfo I, Luong BL: Development and validation of a semi-quantitative food questionnaire based on a population survey (in French). Soz Praventivmed 1994;39:345-369.

32 de Abreu D, Guessous I, Gaspoz JM, Marques-Vidal P: Compliance with the Swiss Society for Nutrition's dietary recommendations in the population of Geneva, Switzerland: a 10-year trend study (1999-2009). J Acad Nutr Diet 2014;114:774-780.

33 Herrmann SD, Heumann KJ, Der Ananian CA, Ainsworth BE: Validity and reliability of the Global Physical Activity Questionnaire (GPAQ). Meas Phys Educ Exercise Sci 2013;17:221-235.

34 Stunkard AJ, Messick S: The three-factor eating questionnaire to measure dietary restraint, disinhibition and hunger. J Psychosom Res 1985;29:71-83.

35 Lluch A: Identification des conduites alimentaires par approches nutritionnelles et psychométriques: implications thérapeutiques et préventives dans l’obésité humaine. Nancy, Université Henri Poincaré, 1995,

36 Sandelowski M: Whatever happened to qualitative description? Res Nurs Health 2000;23:334-340.

37 Astrup A, Raben A, Geiker N: The role of higher protein diets in weight control and obesity-related comorbidities. Int J Obes (Lond) 2015;39:721-726.

38 Catenacci VA, Pan Z, Thomas JG, Ogden LG, Roberts SA, Wyatt HR, Wing RR, Hill JO: Low/no calorie sweetened beverage consumption in the National Weight Control Registry. Obesity (Silver Spring) 2014;22:2244-2251.

39 Mattson MP, Allison DB, Fontana L, Harvie M, Longo VD, Malaisse WJ, Mosley M, Notterpek L, Ravussin E, Scheer FA, Seyfried TN, Varady KA, Panda S: Meal frequency and timing in health and disease. Proc Natl Acad Sci U S A 2014;111:16647-16653.

40 Astrup A, Gotzsche PC, van de Werken K, Ranneries C, Toubro S, Raben A, Buemann B: Meta-analysis of resting metabolic rate in formerly obese subjects. Am J Clin Nutr 1999;69:1117-1122.

41 Camps SG, Verhoef SP, Westerterp KR: Weight loss, weight maintenance, and adaptive thermogenesis. Am J Clin Nutr 2013;97:990-994.

42 Fothergill E, Guo J, Howard L, Kerns JC, Knuth ND, Brychta R, Chen KY, Skarulis MC, Walter M, Walter PJ, Hall KD: Persistent metabolic adaptation 6 years after 'The Biggest Loser' competition. Obesity (Silver Spring) 2016;24:1612-1619.

43 Westenhoefer J, Stunkard AJ, Pudel V: Validation of the flexible and rigid control dimensions of dietary restraint. Int J Eat Disord 1999;26:53-64.

44 Bacon L, Stern JS, Van Loan MD, Keim NL: Size acceptance and intuitive eating improve health for obese, female chronic dieters. J Am Diet Assoc 2005;105:929-936.

45 Mathieu J: What should you know about mindful and intuitive eating? J Am Diet Assoc 2009;109:1982-1987.

46 Dalen J, Smith BW, Shelley BM, Sloan AL, Leahigh L, Begay D: Pilot study: Mindful Eating and Living (MEAL): weight, eating behavior, and psychological outcomes associated with a mindfulness-based intervention for people with obesity. Complement Ther Med 2010;18:260-264. 
Kruseman et al.: Long-Term Weight Maintenance Strategies Are Experienced as a Burden by Persons Who Have Lost Weight Compared to Persons with a lifetime Normal, Stable Weight

47 Greenway FL: Physiological adaptations to weight loss and factors favouring weight regain. Int J Obes (Lond) 2015;39:1188-1196.

48 Malhotra R, Ostbye T, Riley CM, Finkelstein EA: Young adult weight trajectories through midlife by body mass category. Obesity (Silver Spring) 2013;21:1923-1934.

49 Reilly A, Mawn B, Susta D, Staines A, Browne S, Sweeney MR: Lessons learned about primary weight maintenance and secondary weight maintenance: results from a qualitative study. BMC Public Health 2015;15:580.

50 Willett W: Nutritional Epidemiology, ed 3rd. New York, Oxford University Press, 2013.

51 Tooze JA, Subar AF, Thompson FE, Troiano R, Schatzkin A, Kipnis V: Psychosocial predictors of energy underreporting in a large doubly labeled water study. Am J Clin Nutr 2004;79:795-804.

52 Johnson RK, Friedman AB, Harvey-Berino J, Gold BC, McKenzie D: Participation in a behavioral weight-loss program worsens the prevalence and severity of underreporting among obese and overweight women. J Am Diet Assoc 2005;105:1948-1951. 